\title{
EARLY DIAGNOSIS OF HIV IN INFANTS USING DRIED BLOOD SPOT- A RETROSPECTIVE STUDY FROM 2010 TO 2016
}

\author{
Dravid MN1, Shah $P G^{2}$, Dange SC 3 , Adchitre HR ${ }^{4}$, Suryawanshi MM ${ }^{5}$
}

1 Professor and HOD, Department of Microbiology, Shri Bhausaheb Hire Government Medical College, Dhule. ${ }^{2}$ Assistant Professor, Department of Microbiology, Shri Bhausaheb Hire Government Medical College, Dhule. ${ }^{3}$ Assistant Professor, Department of Microbiology, Shri Bhausaheb Hire Government Medical College, Dhule. ${ }^{4}$ Associate Professor, Department of Microbiology, Shri Bhausaheb Hire Government Medical College, Dhule. ${ }^{5}$ Assistant Professor, Department of Microbiology, Shri Bhausaheb Hire Government Medical College, Dhule.

\section{ABSTRACT}

\section{BACKGROUND}

Mother-to-child transmission of HIV is a major cause of HIV in children. Detection of virus by DNA PCR is of utmost importance in $<6$ months of age as antibody detection is not helpful. Dried blood spot (DBS) method is a cheap, less invasive, easy and feasible method as compared to whole blood collection. Followup of babies up to 18 months is needed before declaring them negative. The study was undertaken to know the HIV transmission rates in babies up to 18 months.

\section{MATERIALS AND METHODS}

Sample collection and processing was done strictly according to National AIDS Control Organisation (NACO) guidelines.

\section{RESULTS}

55.36\% HIV positive Antenatal care (ANC) females were in 20-24 years age group. 48.21\% HIV Positive ANC females presented for the first time in $2^{\text {nd }}$ trimester. $53.57 \%$ females were primigravida. In $55.36 \%$ cases, even spouse was positive for HIV. In $78.57 \%$ there was normal delivery. In year 2010, samples collected at 6 weeks, 6 months, 12 months, 18 months were 33, 21, 21 and 20 respectively; and in year 2011 were 32, 18, 9, 29; in 2012 were 30, 28, 23, 16; in 2013 were 33, 30, 25, 14; in 2014 were 30, 14, 19, 23; in 2015 were 27, 21, 20, 14; in 2016 were 14, 17, 15, 12 respectively. The positivity rate at 6 weeks, 6 months, 12 months, 18 months in 2010 were $1,0,1,2$; in 2011 were 4, 0, 0, 1; in 2012 were 2, 0, 0, 0; in 2013 were 1, 1, 0, 0; in 2014, there were no positive cases; in 2015 were $0,1,0,0$; and in 2016 were $0,1,0,0$ respectively.

\section{CONCLUSION}

Decrease in positivity of samples in years 2014-2016 may be due to effective Prevention of Parent-to-child transmission (PPTCT) programme, increase in awareness amongst people, and early initiation of Anti-Retroviral Therapy (ART). The number of samples also reduced significantly in the year 2016. No deaths were recorded after 2011.

\section{KEYWORDS}

ART, DBS, DNA-PCR, NACO, PPTCT, 2010-2016.

HOW TO CITE THIS ARTICLE: Dravid MN, Shah PG, Dange SC et al. Early diagnosis of HIV in infants using dried blood spot- A retrospective study from 2010 to 2016. J. Evolution Med. Dent. Sci. 2017;6(68):4879-4882, DOI: 10.14260/Jemds/2017/1057

\section{BACKGROUND}

In 2012, approximately, 2.3 million new HIV infections occurred worldwide and 1.6 million of these infections were in sub-Saharan Africa. Everyday around 6300 adults are infected worldwide of which $34 \%$ are women aged $15-24$ years. $^{1}$ There are $30 \%$ chances of mother-to-child transmission of HIV infection (transplacental, at birth, after birth, pregnancy). ${ }^{2}$ According to studies, almost 2000 infants in developing countries are infected everyday with HIV through mother-to-child transmission. ${ }^{3}$

Most of the PPTCT programmes have successfully achieved high rates of initial HIV testing in pregnant women. The tests of HIV are repeated if the mother is negative.

Financial or Other, Competing Interest: None.

Submission 20-07-2017, Peer Review 11-08-2017,

Acceptance 19-08-2017, Published 24-08-2017.

Corresponding Author:

Dr. Shah $P G$,

Assistant Professor,

Department of Microbiology,

Shri Bhausaheb Hire Government

Medical College, Dhule.

E-mail: poojashah1688@gmail.com

DOI: $10.14260 /$ jemds $/ 2017 / 1057$
But the partner involvement and testing in mother and child health services is mostly limited to requests in ANC women. ${ }^{4}$ Under PPTCT programme, the exposed children of the seropositive mothers are benefitted. ${ }^{5}$

As maternal antibodies can be present in infants after delivery, antibody testing is not useful to achieve the diagnosis till 18 months. So, detection of virus is of utmost importance. DNA PCR that detects HIV-1 proviral form integrated with human genome has been implemented across world since 2010.5

Whole blood needs to be stored in the refrigerator. Hence, DBS is of much importance. DBS sampling is microvolume sampling technique that involves quantification of analytes from whole blood spotted on filter paper. This technique is discovered in 1960 and since been used for screening newborn errors of metabolism. ${ }^{6}$ Need of less amount of blood and that the sample can be collected and stored without refrigeration with low biological hazard are the advantages of DBS. ${ }^{7}$ Also, a prick is sufficient so use of needles and vacutainer can be avoided. Blood coated on filter paper lyses the cells and binds the DNA. This facility is mainly used in resource limited nations. ${ }^{8}$ The HIV-1 PCR test is $99 \%$ sensitive and $98 \%$ specific which means that a confirmatory test is critical to eliminate the rare cases of false positives. 
As prophylactic antibiotic and antiretroviral therapy can increase the longevity and promotes healthy survival, early diagnosis of HIV should be done. This study was undertaken to assess the detection rate of HIV in infants using DBS. We took the data from year 2010-2016.

\section{MATERIALS AND METHODS}

The present study was carried out retrospectively at Shri Bhausaheb Hire Government Medical College, Dhule from 2010-2016.

All the babies whose mothers were positive for HIV or who were suspected cases of HIV as referred by the clinicians were included in the study. Our study also included babies with unknown identities.

An informed consent from parent or guardian was taken before pre-test counselling and collecting the sample. The sample collection was done according to NACO guidelines. ${ }^{9}$

DBS was collected from heel prick in children aged 6 weeks to 4 months, from big toe in children aged $>4$ months to 10 months and from $3^{\text {rd }}$ and $4^{\text {th }}$ finger prick in children $>10$ months to 18 months.

DBS card was labelled and we filled test requisition and result form (TRRF) just before taking the specimen. DBS samples were stored at $2-8^{\circ} \mathrm{C}$ until transported and packed appropriately. We ensured packaging appropriate specimens after verifying the TRRF and delivery checklist. Transportation of sample in person or through courier was done every Tuesday of the month.

\section{Algorithm for Diagnosis of HIV Infection at $<6$ Months of Age \\ At ICTC Level}

We have collected and sent DBS of babies between 6 weeks to 6 months of age for HIV-1 PCR test to National AIDS Research Institute (NARI) PCR testing laboratory. Antibody testing was not recommended in babies $<6$ months. If baby is $<6$ weeks old, then PCR test is not recommended; 6 weeks and above is the optimal age for the routine first PCR test.

\section{If Result is HIV-1 Detected}

Infant is probably HIV-1 infected. NARI lab asks for another DBS sample. If the sample is positive, baby is HIV-1 infected. We refer the baby to Anti-Retroviral Therapy Centre (ARTC) for treatment. If sample is negative, then lab asks for another DBS sample and will rely on the result of this sample for establishing diagnosis.

\section{If HIV-1 is not detected}

Baby is asked to visit at 6 months of age again or when the baby develops sign and symptoms of HIV (whichever is earlier).

If DBS test is positive, then another sample collected at different time (not 2 samples spotted at same time) were sent for confirming diagnosis.

\section{Algorithm for Diagnosis of HIV Infection at $>6$ Months of Age \\ At ICTC Level \\ Blood was collected and tested for HIV antibodies using all the 3 serological tests (Triline, Trispot and ImmunoComb). Also we prepared a DBS for HIV-1 PCR test simultaneously.}

\section{If all the 3 or any 2 or any 1 of the Serological Tests is Positive}

We send DBS of child for HIV-1 PCR test and follow the Early Infant Diagnosis (EID) testing algorithm. [Serologically unreliable in infants (maternal antibodies cross placenta; can give a positive HIV antibody test in baby), Testing of EID is by qualitative nucleic acid tests (NAT)].

If all the 3 rapid serological tests are negative, baby does not need HIV-1 PCR test at this point. We asked the baby to come back for testing at 6 weeks after the last breastfeeding or at 12 months or if baby develops symptoms of HIV whichever is earlier.

\section{RESULTS}

The current study was conducted at Shri Bhausaheb Hire Government Medical College from year 2010-2016.

The age distribution of ANC females presenting to our department from 2010 to 2016 is as follows.

According to Table I, total 112 ANC females positive for HIV were enrolled in our hospital. Maximum number of females were in 20-24 years age group (55.36\%) and minimum number was recorded in $>35$ years age group (1.79\%).

As per Figure I, 48.21\% females presented for the first time in $2^{\text {nd }}$ trimester of pregnancy, $32.14 \%$ in the third trimester and $19.64 \%$ in the first trimester.

53.57\% HIV Positive ANC females were gravida 1, 32.14\% and $14.29 \%$ were gravida 2 and gravida 3 respectively. (Table II).

According to Figure II, in $55.36 \%$ cases spouse was having history of HIV while in $31.25 \%$ cases the spouse was negative for HIV. In $13.39 \%$ cases, the history could not be traced.

As per Figure III, 78.57\% HIV Positive ANC females delivered by normal delivery while $21.43 \%$ delivered by caesarean section.

In year 2010, samples collected at 6 weeks, 6 months, 12 months, 18 months were 33, 21, 21 and 20 respectively; and in year 2011 were 32, 18, 9, 29; in 2012 were 30, 28, 23, 16; in 2013 were $33,30,25,14$; in 2014 were $30,14,19,23$; in 2015 were $27,21,20,14$; in 2016 were $14,17,15,12$ respectively. The positivity rate at 6 weeks, 6 months, 12 months, 18 months in 2010 were $1,0,1,2$; in 2011 were 4, 0 , 0,1 ; in 2012 were $2,0,0,0$; in 2013 were $1,1,0,0$; in 2014, there were no positive cases; in 2015 were $0,1,0,0$; and in 2016 were $0,1,0,0$ respectively. (Table III).

According to Table IV, 2 babies died in 2010, 1 baby in 2011 and 1 baby migrated in 2016.

\begin{tabular}{|c|c|c|c|c|c|}
\hline Year & $\begin{array}{c}\mathbf{1 5 - 1 9} \\
\text { Years }\end{array}$ & $\begin{array}{c}\mathbf{2 0 - 2 4} \\
\text { Years }\end{array}$ & $\begin{array}{c}\mathbf{2 5 - 3 4} \\
\text { Years }\end{array}$ & $\begin{array}{c}>35 \\
\text { Years }\end{array}$ & TOTAL \\
\hline 2010 & 1 & 11 & 8 & 1 & $21(18.75 \%)$ \\
\hline 2011 & 1 & 9 & 7 & 0 & $17(15.18 \%)$ \\
\hline 2012 & 2 & 10 & 7 & 0 & $19(16.96 \%)$ \\
\hline 2013 & 2 & 7 & 7 & 0 & $16(14.29 \%)$ \\
\hline 2014 & 1 & 10 & 5 & 0 & $16(14.29 \%)$ \\
\hline 2015 & 1 & 9 & 2 & 1 & $13(11.61 \%)$ \\
\hline 2016 & 0 & 6 & 4 & 0 & $10(8.92 \%)$ \\
\hline Total & $\mathbf{8}$ & $\mathbf{6 2}$ & $\mathbf{4 0}$ & $\mathbf{2}$ & $\mathbf{1 1 2}$ \\
\hline $\mathbf{( 7 . 1 4 \% )}$ & $\mathbf{( 5 5 . 3 6 \% )}$ & $\mathbf{( 3 5 . 7 1 \% )}$ & $(\mathbf{1 . 7 9 \% )}$ & \\
\hline
\end{tabular}

Table I. Age-wise Distribution of ANC Females Positive for HIV

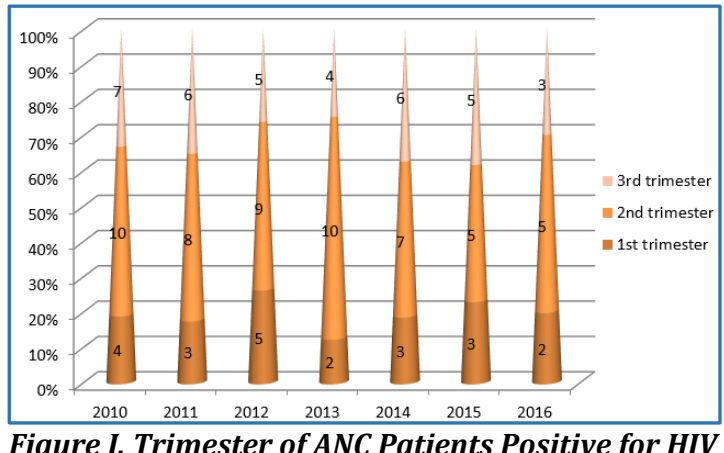

Figure I. Trimester of ANC Patients Positive for HIV 


\begin{tabular}{|c|c|c|c|c|}
\hline Year & Gravida 1 & Gravida 2 & Gravida 3 & Total \\
\hline 2010 & 10 & 7 & 4 & 21 \\
\hline 2011 & 7 & 8 & 2 & 17 \\
\hline 2012 & 9 & 7 & 3 & 19 \\
\hline 2013 & 8 & 5 & 2 & 16 \\
\hline 2014 & 10 & 4 & 1 & 16 \\
\hline 2015 & 9 & 2 & 1 & 10 \\
\hline 2016 & 7 & $\mathbf{3 6}(32.14 \%)$ & $\mathbf{1 6}(14.29 \%)$ & $\mathbf{1 1 2}$ \\
\hline Total & $\mathbf{6 0}(53.57 \%)$ & \multicolumn{2}{c}{} \\
\hline
\end{tabular}
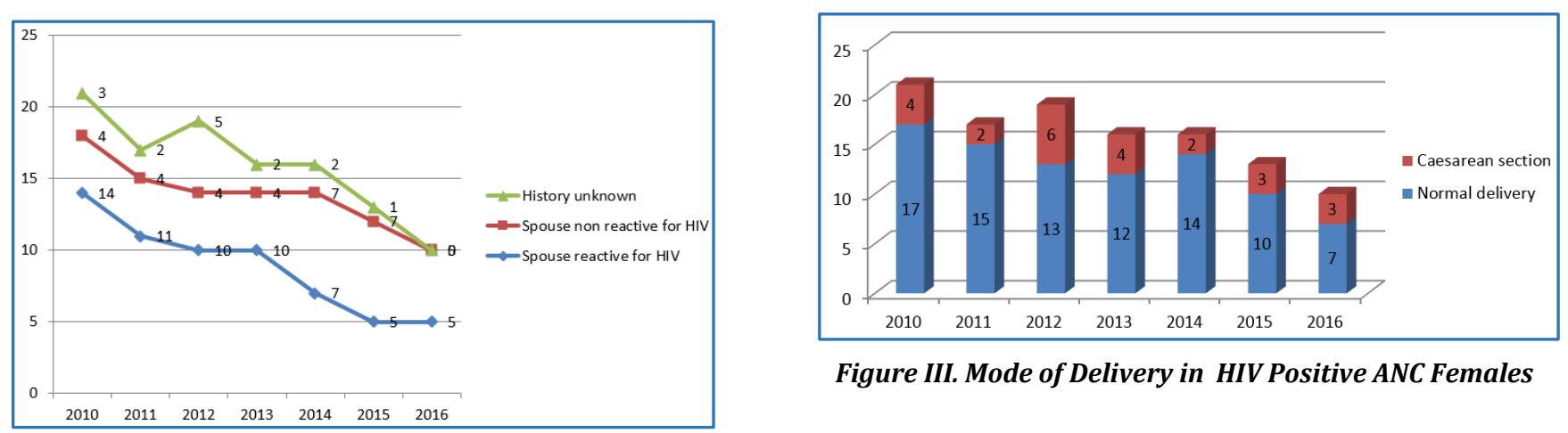

Figure III. Mode of Delivery in HIV Positive ANC Females

Figure II. Status of Spouse Positive,

Negative or having Unknown History of HIV

\begin{tabular}{|c|c|c|c|c|c|c|c|c|c|}
\hline Sl. No. & Year & 6 weeks Test & Positive & 6 months Test & Positive & 12 months Test & Positive & 18 months Test & Positive \\
\hline 1 & 2010 & 33 & 1 & 21 & 0 & 21 & 1 & 20 & 2 \\
\hline 2 & 2011 & 32 & 4 & 18 & 0 & 9 & 0 & 29 & 1 \\
\hline 3 & 2012 & 30 & 2 & 28 & 0 & 23 & 0 & 16 & 0 \\
\hline 4 & 2013 & 33 & 1 & 30 & 1 & 25 & 0 & 14 & 0 \\
\hline 5 & 2014 & 30 & 0 & 14 & 0 & 19 & 0 & 23 & 0 \\
\hline 6 & 2015 & 27 & 0 & 21 & 1 & 20 & 0 & 14 & 0 \\
\hline 7 & 2016 & 14 & 0 & 17 & 1 & 15 & 1 & 12 & 0 \\
\hline Total & $\mathbf{2 0 1 0 - 2 0 1 6}$ & $\mathbf{1 1 9}$ & $\mathbf{8 ( 6 . 7 2 \% )}$ & $\mathbf{1 4 9}$ & $\mathbf{3 ( 2 . 0 1 \% )}$ & $\mathbf{1 3 2}$ & $\mathbf{2 ( 1 . 5 2 \% )}$ & $\mathbf{1 2 8}$ & $\mathbf{3 ( 2 . 3 4 \% )}$ \\
\hline
\end{tabular}

Table III. Number of Tests Conducted and Positive for HIV at 6 Weeks, 6 Months, 12 Months and 18 Months Respectively

\begin{tabular}{|c|c|}
\hline Year & Fate of the Baby \\
\hline 2010 & 2 babies died \\
\hline 2011 & 1 baby died \\
\hline 2012 & No deaths \\
\hline 2013 & No deaths \\
\hline 2014 & No deaths \\
\hline 2015 & No deaths \\
\hline 2016 & 1 baby migrated \\
\hline $2010-2016$ & 3 deaths, 1 migration \\
\hline \multicolumn{2}{|c|}{ Table IV. Fate of the HIV Positive Babies } \\
\hline
\end{tabular}

\section{DISCUSSION}

In India, it is estimated that currently about 115,000 children are living with HIV, and approximately 40,000 children below 15 years are provided with antiretroviral therapy (ART) by the national program. While $35 \%$ children infected with HIV do not see their first birthday, $53 \%$ do not celebrate their second birthday. ${ }^{10}$ Hence, early diagnosis and testing is of utmost importance.

In our study, total 112 ANC females who were tested as HIV positive were included. 20-24 years age group was the most commonly affected. $55.36 \%$ females were in this age group followed by 25-34 years (35.71\%), 15-19 years $(7.14 \%)$ and $>35$ years $(1.79 \%)$. (Table I). This correlates with the study of Sumitra Yadav et al in which $60 \%$ of the females were in 20-25 years age group. ${ }^{11}$ This also correlates

with the study of Maia et al in which $<30$ years was the most commonly affected age group. ${ }^{12}$ In the study of Berhan et al, 25-34 years age group was most affected (59.9\%) with HIV in ANC patients. ${ }^{13}$ The age variation depends upon age at the time of marriage and infectivity of the partner.

The reason for less number of visits in first trimester may be ignorance, lack of awareness regarding pregnancy, lack of hospital facilities especially in rural areas and late diagnosis of pregnancy.

According to Table II, 53.57\% HIV infected females were primigravida, $32.14 \%$ were gravida 2 and $14.29 \%$ were gravida 3. This is in contrast to the study of Sumitra Yadav et al in which $70 \%$ of affected ANC females were gravida 2 and $10 \%$ each of G1, G3 and G4.11 This result also varies individually and depends on age at the time of exposure and infectivity of partner, in case of home deliveries HIV status may be unknown.

According to Figure II, 55.36\% spouses were also reactive for HIV, $31.25 \%$ were non-reactive for HIV and in $13.39 \%$ cases the history of HIV was unknown in the spouses. The reason for not knowing HIV status in $13.39 \%$ cases was partner not willing to come for HIV testing, social stigma of HIV, lack of awareness and ignorance about the disease. Single motherhood, rural residence, low maternal education, and higher paternal age were associated with unknown HIV status. In the study of Maia et al, $23.65 \%$ cases had their partners infected with HIV. ${ }^{12}$ 
In our study, as per Figure III, 78.57\% females delivered by normal delivery and $21.43 \%$ females delivered by Caesarean section. There are more chances of transmission of HIV through normal delivery as there is more exposure of mucosal surface of baby in normal delivery as compared to Caesarean section. This finding correlates with the study of Hondegla et al, Kaizad et al, Berhan et al and Sumitra Yadav et al. ${ }^{11,13,14,15}$

As mother-to-child transmission rates have been reported in USA and Western European untreated populations as 15$20 \%$; in developing countries, rates were as high as $40 \% .{ }^{14}$

In our study, according to Table III, the infectivity rate in infants of HIV positive mothers was $3.03 \%$. In the study of Hondegla et al, the infectivity rate was $5.6 \% .{ }^{15}$ They conducted a 2-year retrospective study. In the study of Oladeinde et al, the HIV prevalence was $10.2 \% .{ }^{16}$ Decrease in mother-to-child transmission rate may be due to increase in awareness, proper counselling, availability of drugs free of cost which decreases mother-to-child transmission.

So, as per Table III, samples positive at 6 weeks were $6.72 \%, 6$ months were $2.01 \%, 12$ months were $1.52 \%, 18$ months were $2.34 \%$. In the study of Berhan et al, samples tested at 6 weeks, 6 weeks to 6 months and after 6 months were 120, 255 and 69 respectively and samples positive at 6 weeks, 6 weeks to 6 months were 6 (5\%), 14(5.49\%), 24 (34.78\%). ${ }^{14}$ In the study of Olana et al, $4.2 \%$ were positive at 6-8 weeks. ${ }^{17}$ In the study of Sumitra Yadav et al, the HIV positive infants at 6 weeks were $4.27 \%, 6$ months were $0.61 \%$ and 18 months were $1.21 \% .11$

According to Table IV, 2 babies died in 2010, 1 baby in 2011 and 1 baby migrated in 2016 i.e. there were $18.75 \%$ deaths and $6.25 \%$ migrations. In the study of Sumitra Yadav et al, $20 \%$ of babies died and $20 \%$ lost to followup which correlates with our study. ${ }^{11}$ The reason for death may be premature labour, missed dose of nevirapine at the time of labour and low birth weight.

\section{CONCLUSION}

HIV remains the important cause of mortality and morbidity amongst children. Diagnosis of HIV in mother during ANC is important. As serological tests are not useful during first 6 months of age, diagnosis by DNA PCR should be done. DBS is an easy, cheap, readily available test requiring very less amount of sample. In our study, there was much decrease in positivity of samples in year 2014-2016. This may be due to effective PPTCT programme, increase in awareness amongst people, free testing of HIV everywhere and early initiation of ART therapy. The number of samples also reduced significantly in the year 2016. No deaths were recorded after 2011.

\section{ACKNOWLEDGEMENTS}

We would like to thank our HIV technician Mr. Rahul Khairnar and Counsellor of PPTCT Ms. Leelashri Nerkar for their contribution in the study.

\section{REFERENCES}

[1] UN AIDS report on the global AIDS epidemic 2013. Geneva: Joint United Nations programme on HIV/AIDS. 2013.

[2] Paniker CK. Anantnarayan and Paniker's textbook of Microbiology. Chapter 61. Human Immunodeficiency virus: AIDS. $8^{\text {th }}$ edn. Chennai: Universities Press, India Private Limited., 2009:570-85.

[3] Antiretroviral for treating pregnant women and preventing HIV infection in infants. Guidelines on care, treatment and support for women living with HIV/AIDS and their children in Resource-constrained settings. Geneva: World Health Organisation, 2004.

[4] Ditekemena J, Koole O, Engmann C, et al. Determinants of male involvement in maternal and child health services in sub-Saharan Africa: a review. Reprod Health 2012;9:32.

[5] Joshi U, Oza U, Solanki A, et al. Early infant diagnosis of HIV in India-early results and sero-positivity determinants. Open Journal of Preventive Medicine 2012;2(3):318-25.

[6] Bhattacharya K, Wotton T, Wiley V. The evolution of blood-spot newborn screening. Transl Pediatr 2014;3(2):63-70.

[7] Mehta N, Trzmielina S, Nonyane BA, et al. Low cost HIV-1 diagnosis and quantification in dried blood spots by real time PCR. PLoS One 2009;4(6): e5819.

[8] Beck IA, Drennan KD, Melvin AJ, et al. Simple, sensitive and specific detection of human immunodeficiency virus type 1 subtype B in dried blood samples for infant diagnosis in the field. J Clin Microbiol 2001;39(1):29-33.

[9] Guidelines on HIV testing. National AIDS control organisation, Ministry of Health and Family Welfare. 2007.

[10] Chandra J, Yadav D. Early Infant Diagnosis of HIV. Indian Pediatrics 2015;52:293-5.

[11] Yadav S, Joshi R, Kale V. Study of factors affecting maternal and fetal outcome in HIV positive women. Int J Reprod Contracept Obstet Gynecol 2017;6:256-61.

[12] Butsashvili M, Kajaia M, Kamkamidze G, et al. Factors associated with HIV testing history among Pregnant women and their partners in Georgia: the ANRS 12127 Prenahtest trial. AIDS Research and Treatment Article ID 356090, 2014;2014: p. 6 . http://dx.doi.org/10.1155/2016/356090.

[13] Berhan Z, Abebe F, Gedefaw M, et al. Risk of HIV and associated factors among infants born to HIV positive women in Amhara region, Ethiopia: a facility based retrospective study. BMC Research Notes 2014;7:876.

[14] Kaizad RD, Parikshit DT, Mamatha ML. Recent trends in mother-to-child transmission of HIV in pregnancy. J Obstet Gynecol India 2010;60(5):395-402.

[15] Hondegla AB, Djeha A, Evi KL, et al. Outcome of infants born to HIV positive women through the aspects of prevention of mother-to-child transmission in Lome (Togo, West Africa) from 2008-2010. Journal of AIDS and HIV Research 2016;8(7):100-7.

[16] Oladeinde BH, Phil RO, Olley M, et al. Prevalence of HIV and anemia among pregnant women. N Am J Med Sci 2011;3(12):548-51.

[17] Olana T, Bacha T, Worku W, et al. Early infant diagnosis of HIV infection using DNA-PCR at a referral center: an 8 years retrospective analysis. AIDS Res Ther 2016;13:29. 